\title{
Experiência docente no ensino da disciplina de metodologia da pesquisa qualitativa na pós-graduação
}

\section{Professor's experience in the teaching of the methodology of qualitative research subject in graduate programs}

\section{Experiencia docente en la enseñanza de la disciplina de metodología de la investigación cualitativa en la postgrado}

http://dx.doi.org/10.221713/2358-2332.2016.v14.1295

Vera Lucia Mendes de Paula Pessoa, doutora em Enfermagem pela Universidade Federal do Ceará (UFC), professora-adjunta e pesquisadora do Grupo de Pesquisa Epidemiologia, Cuidado em Cronicidades e Enfermagem (GRUPECCE) da Universidade Estadual do Ceará (Uece), Fortaleza, CE, Brasil. E-mail: vera.mendes@uece.br.

Maria do Socorro de Sousa, doutora em Saúde Coletiva pela Universidade Federal do Ceará (UFC) e bolsista Prodoc-Capes do Programa de Pós-Graduação em Saúde Pública da UFC, Fortaleza, CE, Brasil. E-mail: sousams3@gmail.com.

Márcia Maria Tavares Machado, doutora em Enfermagem em Saúde Comunitária pela Universidade Federal do Ceará (UFC), professora associada do Doutorado e Mestrado do Programa de Pós-Graduação em Saúde Pública da UFC, Fortaleza, CE, Brasil. E-mail: marciamachadoufc@gmail.com.

\section{Resumo}

O trabalho, ora apresentado, traz como objetivo a descrição da experiência da inserção de professoras em estágio pós-doutoral na disciplina de métodos e técnicas em pesquisa qualitativa em um programa de pós-graduação em Saúde Coletiva. A relevância de tal empreitada decorre do fato de que, diferentemente da metodologia quantitativa, a abordagem qualitativa não tem sido, ainda, uma opção de primeira escolha nas ciências da saúde para exploração de questões advindas da realidade. A experiência evidencia as aprendizagens das docentes, quando acolhem o conhecimento prévio do estudante, valorizam os relatos de experiências de pesquisa e proporcionam um exercício prático de técnica. Ao término dessa construção, constata-se que o repensar de práticas pedagógicas fez a criatividade e inventividade se tornarem presente na práxis docente.

Palavras-chave: Experiência. Pesquisa Qualitativa. Pós-Graduação.

\footnotetext{
${ }^{1}$ Como citar: ABNT NBR 6023:2002 e incluir o DOI.
} 
Pessoa, Sousa e Machado / Experiência docente no ensino da disciplina de metodologia da pesquisa qualitativa na pós-graduação

\begin{abstract}
This manuscript aims to describe the experience of the insertion of postdoctoral professors in the methods and techniques in qualitative research subject in a graduate program in Collective Health. The relevance of this work stems from the fact that, unlike the quantitative methodology, the qualitative approach has not yet been a first-choice option in Health Sciences for exploring issues arising from reality. The experience evidences the learning of the professors when receiving the previous knowledge of the student, valuing the reports of research experiences and providing a practical technique. At the end of this process, we verified that the rethinking of pedagogical practices made creativity and inventiveness become present in the teaching praxis.
\end{abstract}

Keywords: Experience. Qualitative Research. Graduate Studies.

\title{
Resumen
}

El presente manuscrito trae como objetivo la descripción de la experiencia de la inserción de profesoras en etapa postdoctoral en la disciplina de métodos y técnicas en investigación cualitativa en un programa de postgrado en Salud Colectiva. La relevancia de tal trabajo se deriva del hecho de que, a diferencia de la metodología cuantitativa, el abordaje cualitativo no ha sido aún una opción de primera elección en las ciencias de la salud para la exploración de cuestiones derivadas de la realidad. La experiencia evidencia los aprendizajes de las docentes, cuando acogen el conocimiento previo del estudiante, valoran los relatos de experiencias de investigación y proporcionan un ejercicio práctico de técnica. Al término de esa construcción, se constata que el repensar de prácticas pedagógicas hizo que la creatividad y la inventividad se hicieran presentes en la praxis docente.

Palabras clave: Experiencia. Investigación Cualitativa. Postgrado.

\section{INTRODUÇÃO}

O conteúdo relacionado à disciplina que envolve métodos e técnicas qualitativas é adicionado à proposta curricular dos cursos de pós-graduação com o propósito de ampliar possibilidades para discussão dos objetos de estudo trazidos para desenvolvimento de dissertações e teses.

Diferentemente da metodologia quantitativa, a abordagem qualitativa não tem sido, ainda, uma opção de primeira escolha na área da saúde para exploração de questões advindas da realidade. Por outro lado, chama atenção o fato de que a produção científica subsidiada em fundamentos teóricos qualitativos apresente substancial incremento, como demonstrado por Bassora e Campos (2010). Contudo, para consolidá-la plenamente e utilizá-la para ampliar o conhecimento em diversas áreas da saúde, deparamos com vários desafios. No que concerne aos cursos de Saúde Coletiva, destacamos o desafio da formação de pesquisadores qualitativos, pois os estudantes são egressos de distintas formações na saúde ou de outros campos, nos quais o enfoque qualitativo é ausente ou insignificante (BOSI, 2012; 2015; BOSI; MACEDO, 2014). 
Pessoa, Sousa e Machado / Experiência docente no ensino da disciplina de metodologia da pesquisa qualitativa na pós-graduação

Taquette e Minayo (2015), ao pesquisarem o ensino-aprendizagem da abordagem qualitativa em Medicina, reconhecem que as pesquisas nas ciências da saúde, em sua maioria, são desenvolvidas com métodos quantitativos e consideram que o uso do método qualitativo de pesquisa por médicos depende fortemente de investimento na formação desses profissionais desde a graduação. Entretanto, existe uma aparente tendência na utilização da abordagem qualitativa na produção de pesquisas relativas à educação médica com progressiva valorização de diferentes métodos qualitativos (BATISTA et al., 2016).

Esta realidade se evidencia nos programas de pós-graduação quando a disciplina de metodologia qualitativa não é obrigatória, pela predominância do paradigma positivista na construção do modo de fazer ciência, o que de todo não parece ser a razão única. Para Taquette e Minayo (2015), o uso da abordagem qualitativa por profissionais da saúde tem forte influência de aspectos como a neutralidade e a generalização que direciona a produção desses profissionais à utilização de outros recursos metodológicos, deixando de ampliar o conhecimento e as competências necessárias ao desenvolvimento de investigações que abordem questões subjetivas e relacionais relevantes para a saúde.

As produções existentes se restringem, na maioria das vezes, a manuais normativos e listagem de diferenciação entre as abordagens qualitativa e quantitativa. Além disso, os pesquisadores qualitativos são marginalizados em algumas instituições e em espaços dedicados às publicações (BENJUMEA, 2015).

Acentuamos, no entanto, o crescente incremento do uso do método qualitativo como alternativa eficiente para resposta de questões de saúde, nos âmbitos coletivo ou individual. Bosi (2012) justifica essa mudança, observando que a complexidade de problemas envolvidos na existência humana não é passível de respostas tão somente por meio de um modelo tradicional. Aqui reside o terreno propício para utilização de recursos outros que favoreçam um olhar distinto da realidade.

Nesta perspectiva e realidade desafiante, insere-se a disciplina de Métodos e Técnicas em Pesquisa Qualitativa, no Programa de Pós-Graduação Stricto Sensu em Saúde Coletiva, da Universidade Federal do Ceará. Com o propósito de envolver o discente em uma atitude mais reflexiva e motivadora, todo conteúdo é planejado em busca de uma proposta emancipatória e crítica que rompa com os modelos tradicionais de ensino e foque no diálogo, na relação entre professor e aluno e na reflexividade de ambos.

Acreditamos que esse ambiente de ensino-aprendizagem seja terreno fértil para a construção de um mundo comum, onde todos sejam vistos e ouvidos na sua singularidade, por meio da palavra compartilhada (CARVALHO, 2014). Tal espaço, em que a construção do conhecimento se organiza de modo conjunto, também se mostrou promissor para novas experiências docentes. Nele, fomos acolhidas de modo singular pela docente responsável pela disciplina, que nos lançou o desafio de repensar práticas há muito consolidadas e estagnadas em um mesmo modo de apresentar conteúdos relacionados com ensino de métodos e técnicas inerentes à pesquisa qualitativa. Percebendo um representativo ganho adicional para nossa formação, aceitamos o desafio, reconhecendo-o como espaço formativo por excelência.

A falta de atenção à formação docente vem sendo percebida ao longo da história em todas as áreas. Com a promulgação da Lei de Diretrizes e Bases da Educação Nacional no 9.394 (BRASIL, 1996), ocorreram mudanças na política do ensino de pós-graduação, especialmente 
Pessoa, Sousa e Machado / Experiência docente no ensino da disciplina de metodologia da pesquisa qualitativa na pós-graduação

em relação à formação de docentes para ensino superior. O Artigo 66 da citada Lei afirma que a preparação para o exercício do magistério superior deverá ser prioritariamente em programas de mestrado e doutorado. Desse modo, ao participar como docente da disciplina também a reconhecemos como um espaço formativo docente no estágio pós-doutoral, algo pouco institucionalizado.

Como a formação docente para o ensino superior é, prioritariamente, desenvolvida nos programas de pós-graduação stricto sensu, há uma associação da pesquisa com a pós-graduação e do ensino com a graduação, ocasionando uma ruptura entre ensino e pesquisa (BATISTA; SILVA, 2001), além de um grande déficit didático-pedagógico na formação docente. Magalhães et al. (2016) reafirmam a ideia que a pós-graduação brasileira, historicamente, objetivou a formação para a pesquisa, secundarizando, ou mesmo colocando à margem, os processos formativos para a docência universitária. Desta forma, nosso desafio era duplo: ver a disciplina como espaço formativo e ensinar um conteúdo também deixado à margem.

A partir do reconhecimento de que a pós-graduação trata da formação de profissionais motivados e adequadamente preparados para transformar a realidade da saúde brasileira (SOUZA; HORA, 2014), a proposta da disciplina, para o campo das investigações em saúde, é contribuir para o desenvolvimento de análises que privilegiam a busca de outros significados dos processos de adoecer e morrer em diferentes populações humanas, por meio da incorporação de estratégias metodológicas de tipo qualitativo. Essa proposta considera que os processos da saúde e da doença estão sujeitos a um conjunto de influências sociais e culturais que extrapolam sua dimensão biológica. Os conteúdos e métodos desta disciplina pretendem colaborar com estudos pensados e construídos sobre uma perspectiva complementar, desde o momento de construção dos objetos de pesquisa até a interpretação dos dados e informações coletadas.

A disciplina tem como objetivos discutir aspectos teórico-metodológicos desenvolvidos na abordagem qualitativa aplicada ao campo de estudos de saúde, além de discorrer sobre estratégias de investigação que contemplem análises quantitativas e qualitativas de forma complementar. Dentro de uma perspectiva crítica, propõe a reflexão sobre as possibilidades de desenvolvimento de projetos de pesquisa no campo de estudos em saúde, que contemplem objetos passíveis de análise qualitativa.

Sem pretensão de aprofundar um estado da arte do assunto ou apresentar um modelo para a prática docente, o presente artigo objetiva descrever a experiência da inserção de professoras em estágio pós-doutoral na disciplina de Métodos e Técnicas em Pesquisa Qualitativa do Programa de Pós-Graduação em Saúde Coletiva na Universidade Federal do Ceará, considerando o (re)significado do saber da experiência docente, desde o planejamento da disciplina até o contato direto com os alunos. A relevância de tal empreitada pode ser apreendida no crescimento pessoal das autoras, pela possibilidade de desconstrução e reconstrução do modo de se desenvolver conteúdos significativos para elaboração do conhecimento científico. Na sequência, narraremos esta experiência, evidenciando o que apreendemos como docentes. Com base na compreensão de experiência como aquilo que nos passa, o que nos acontece e o que nos toca (LARROSA, 2014) como sujeitos da experiência, apresentaremos nossa disponibilidade de ensinar e aprender em torno de tópicos relacionados ao ensino da abordagem qualitativa. Acredita-se que a educação faz seus protagonistas voltarem 
Pessoa, Sousa e Machado / Experiência docente no ensino da disciplina de metodologia da pesquisa qualitativa na pós-graduação

à experiência, para que ao retomá-la possam descobrir novos caminhos e significados. (CONTRERAS; LARA, 2010).

\section{O PLANEJAMENTO: O QUE INOVAR? COMO RENOVAR?}

Ao sermos inseridas no planejamento da disciplina, em conjunto com a docente responsável, fomos provocadas pelo seguinte questionamento: o que podemos trazer de novo? Como discutir, reflexivamente, conteúdos tradicionalmente e amplamente divulgados nos manuais de pesquisa? Os conteúdos já estavam estabelecidos na ementa da disciplina e não podiam ser alterados, mas, como nosso compromisso era com pesquisadores em formação, foi necessário que o conteúdo dessa disciplina reunisse conhecimentos e informações pertinentes à formação de pesquisadores. Para atender a essa exigência, tomamos como base os princípios ensinados por Morin (2000) para o segundo milênio, ao afirmar que o conhecimento pertinente não é fundado em uma sofisticação, mas numa atitude que consiste em contextualizar o saber. Em situar as informações num contexto global e, se possível, num contexto geográfico histórico, um conhecimento simultaneamente analítico e sintético das partes religadas ao todo e do todo religado às partes, que reconheça a multidimensionalidade, o complexo.

Assim, nossa primeira tarefa foi situar a disciplina: Métodos e Técnicas em Pesquisa Qualitativa, na totalidade do projeto pedagógico do programa de pós-graduação stricto sensu, ao ensino em Saúde Coletiva no Brasil. O artigo de Barata e Santos (2013) nos apresentou os desafios para a pós-graduação em Saúde Coletiva no início do século XXI e as repercussões para a formação, que deve considerar: a necessidade de formar pesquisadores capazes de identificar problemas de pesquisa coerentes com as necessidades de saúde; a sólida formação teórica e metodológica; possibilidade de interagir com pesquisadores de outros campos disciplinares e outras capacidades.

Com base em Larrosa (2014) indagamos: o que se compreende por uma sólida formação teórica e metodológica? Tratamos de uma formação que deixa o sujeito com muita informação e, como ator social moderno, ainda capaz de opinar? Ou aquele que se expõe atravessando um espaço indeterminado, fazendo do método um caminho que se faz ao percorrer, sujeito da experiência de pesquisar?

Um planejamento educacional que atenda a estas características não pode se restringir a responder tecnicamente a indagação de como ensinar, necessitando questionar para que ensinar, por que e a favor de quem. Pimenta e Anastasiou (2002, p. 208) acrescentam que nas aulas, para além "do quê" e "do como", deve-se ensinar também "a pensar", ações determinantes e que e se condicionam mutuamente, configurando o ensino como atividade do professor e do aluno. Pensar é dar sentido ao que somos e o que nos acontece (BONDÍA, 2002). Percebemos, então, as possibilidades de inovar, mesmo com os conteúdos pré-estabelecidos.

O significado dado aos temas "inovação", "inovar" e "novo" no ensino superior, reveste-se de uma polissemia, desde sua concepção até a abrangência e a profundidade da alteração implementada (MASETTO, 2012). Optamos pela visão de inovação educacional como conjunto de decisões, intervenções e processos orientados por intencionalidade, que nos fez acreditar na possibilidade de inovar no espaço da pós-graduação, renovando o sentido do papel docente com a superação do modelo centrado na fala que faz o dizer do conteúdo como 
Pessoa, Sousa e Machado / Experiência docente no ensino da disciplina de metodologia da pesquisa qualitativa na pós-graduação

ato predominante do ensino e a repetição do aluno como ato da aprendizagem (PIMENTA; ANASTASIOU, 2002).

Decidimos que nossa abordagem seria a mais próxima possível de aspectos práticos, pois não queríamos ser professoras palestrantes. O número de alunos matriculados nos auxiliou sobremodo, pois, por se tratar de uma disciplina optativa no doutorado em Saúde Coletiva, contamos com a participação de cinco alunos. Estes, de modo geral, tinham como proposta metodológica para o desenvolvimento de suas teses, a abordagem qualitativa.

O planejamento foi orientado por uma construção coletiva, rompendo com a mera divisão de tarefas ou o pensar isolado e individual. Para Anastasiou e Alves (2010), pensar coletivamente uma disciplina nos conduz a outro tipo de trabalho, que exige a escuta do outro, sem descuidar de uma discussão aprofundada da finalidade e objetivos de aprendizagem pretendidos. Caracterizou-se, assim, o compromisso grupal com o todo da ação docente e o posicionamento da importância de momentos fora da sala de aula. Partimos da premissa de que o pesquisador qualitativo constrói conhecimento a partir da realidade e, para tanto, seria fundamental esse encontro com as experiências do mundo, que o aluno assumisse o rumo da sua autoformação na condição de sujeito.

$\mathrm{Na}$ primeira reunião, retomamos os planos de ensino anteriores, a forma que era trabalhada a disciplina e as possibilidades para um replanejamento. Tal iniciativa foi norteada pela compreensão de que nenhuma prática inovadora começa do zero; seu desenvolvimento está relacionado ao contexto histórico, necessidades e carências sentidas pelo grupo para quem as respostas existentes já não satisfazem mais, tendo em vista melhores resultados (HERNÁNDEZ, 2000).

A partir dessa compreensão, utilizamos o (re)-novar. Considerando o (re) como paradigma em conformidade com o apresentado por Morin (2001), quando reitera que ele não pode ser associado a uma repetição inócua, mas sim ao recomeço, a partir da reflexão de práticas previamente existentes - que possui conteúdo fundamental e inovador. Tínhamos em mente que planejávamos para dar certeza e precisão própria à ação, explicitando os fundamentos nela presentes (GANDIN, 2005). Desse modo, o planejamento se constituiria como um momento de trocas e melhor entendimento da ação de ensinar e de aprender (ANASTASIOU; ALVES, 2010).

$\mathrm{Na}$ fundamentação da ação docente, foi imprescindível refletir sobre o compromisso social da universidade e dos cursos de pós-graduação, tornando-se necessárias as discussões sobre o conceito de ciência, de pesquisa e de conhecimento como construção mediada pelo diálogo enquanto encontro dos homens que se solidarizam no refletir e no agir como seus sujeitos endereçados ao mundo a ser transformado e humanizado (FREIRE, 1987). Assim apreendido, o diálogo não pode reduzir-se a um ato de depositar ideias de um para o outro, tampouco se tornar simples troca de experiência a ser consumidas pelos permutantes.

Os conteúdos escolhidos para composição do plano de disciplina não se caracterizavam pela excepcionalidade. A perspectiva de renovação residia no sentido atribuído à postura docente da pós-graduação, favorecendo o estímulo à reflexão e à construção singular de conhecimentos por parte dos discentes. Tendo como pontos de partida questionamentos lançados ao grupo docente e discente, acreditamos ser possível o emergir de experiências próprias e, consequentemente, a reflexão dos conhecimentos prévios. Tal como Arendt, 
Pessoa, Sousa e Machado / Experiência docente no ensino da disciplina de metodologia da pesquisa qualitativa na pós-graduação

esperávamos que os doutorandos se deixassem contaminar pela perplexidade de re-conhecer conteúdos amplamente debatidos, agora sob uma ótica pessoal (CORREIA, 2014).

Tomamos como consensual a compreensão de que os conteúdos seriam apresentados de forma dialogada e apoiados por textos, artigos e trocas de experiências. Concordamos com Larrosa (2014) ao observar que a experiência não é o que acontece, mas o que nos ocorre; por isto, ela é singular e impossível de ser repetida, a menos que seja, de algum modo, revivida e tornada própria. Priorizamos a experiência dos pesquisadores qualitativos do programa para incentivar os alunos a reviverem os métodos e técnicas utilizadas, acreditando na singularidade do caminhar de cada um. Assim, os alunos foram estimulados a realizar entrevista e aplicar a técnica do grupo focal como experiência positiva no sentido de provar e experimentar. Não desejávamos fazer aulas expositivas destas técnicas, mas criar possibilidades dos pesquisadores qualitativos experimentarem, considerando que informação não é experiência e não deixa lugar para isto (LARROSA, 2014).

Ancoradas nas ideias de experiências, citadas anteriormente, nós, professoras, abandonamos as aulas expositivas tradicionais e investimos no risco de experimentar, na pósgraduação, a aposta pedagógica focada nas rodas dialógicas, fundamentadas nos princípios epistemológicos e na ambiência pedagógica participativa do Círculo de Cultura Freireano. O diálogo circular intersubjetivando-se mais e mais vai assumindo, criticamente, o dinamismo de subjetividade criadora, na qual, todos juntos, docentes e discentes e em colaboração, reelaboram o mundo.

Paulo Freire (1987) nos alerta que, a rigor, não se ensina, mas se aprende em reciprocidade de consciências. Assim compreendido, o professor se torna um coordenador do processo educativo, que tem por função dar as informações essenciais, solicitadas pelos participantes, e propicia, principalmente, as condições favoráveis à dinâmica do grupo. Nestas condições, inclui-se, também, chegar antecipadamente na sala de aula, para reorganizar as cadeiras que ainda permanecem em fila, organização vista até hoje, praticamente em todos os graus de ensino e instituições, como indicador de ordem. Colocar as cadeiras em roda facilita que cada pessoa se posicione uma ao lado da outra, em um encontro possível de se conversar sobre a vida cotidiana, na condição de sujeito. Os docentes, acolhendo os discentes já na própria roda, apresentam-na como espaço potencial do diálogo em movimento circular, onde se pode escutar, falar, refletir, socializar pesquisas e compartilhar experiências. Nesse sentido, Freire (1987) lembra, ainda, que a colaboração, característica da ação dialógica, não pode ocorrer a não ser entre sujeitos, ainda que tenham níveis distintos de função, de responsabilidade, como em sala de aula.

Tal iniciativa vai ao encontro das premissas inerentes à abordagem qualitativa, com a valorização do sujeito e do mundo exterior no espaço da sala de aula. Os aspectos teóricos, as técnicas de investigação, o pesquisador e o trabalho de campo nos estudos qualitativos na saúde seriam componentes dos diálogos que pretendíamos estabelecer. A inovação do grupo de docentes se caracterizava pelo abandono da docência da eminência, na qual o saber do professor de modo algum poderá ser suplantado, restando ao aluno ouvir o monólogo interminável de experiências outras, tantas vezes distante de sua própria realidade sem afetá-lo.

O grupo de docentes reorganizou suas ações em sete encontros presenciais, compreendendo que aula não deve ser dada e nem assistida, mas construída em ação conjunta 
Pessoa, Sousa e Machado / Experiência docente no ensino da disciplina de metodologia da pesquisa qualitativa na pós-graduação

entre professor e aluno. A escolha por encontro e não aula se deu por acreditarmos nesses espaços como ato de revisitar, de ir ao mundo do outro. Segundo Pimenta e Anastasiou (2002), a intencionalidade do conceito de "ensinagem" exige do professor a competência docente de planejar e efetivar um processo contínuo de ações. Nesta perspectiva, deixamos claro o que pretendíamos como docentes. Ao mesmo tempo, buscamos articulação e coerência entre os objetivos, conteúdos e procedimentos, tendo em vista a influência destes no processo de aprendizagem vivenciado por docentes e discentes, no movimento de formação recíproca.

A maneira de organizar os encontros, o tipo de incentivo, as expectativas que depositamos e os materiais que utilizamos, veiculam decisões tomadas em relação a determinada experiência educativa (ZABALA, 1998, 2002), estando ligadas a referenciais que nos conduzem às seguintes reflexões: para que educar? Para que ensinar? Em qualquer dos casos, a fonte socioantropológica está determinada pela concepção ideológica que condiciona e delimita o papel e o sentido que terá a fonte epistemológica. O autor supracitado lembra, ainda, que as fontes psicológica e didática também estão estreitamente inter-relacionadas, pois, mesmo em planos diferentes, não podemos responder como ensinar, sem sabermos como as aprendizagens se produzem. Tal experiência poderá ser inovadora, renovadora ou reprodutora de um tipo de sociedade, universidade ou, ainda, do papel docente, se não houver reflexão profunda e permanente quanto à condição de cidadão e cidadã e quanto às características da sociedade em que viverão.

Perguntamo-nos, então: para que educar ou ensinar pesquisadores a dominarem a abordagem qualitativa? Como ensiná-los, sem deixar de considerar como as aprendizagens acontecem? E quais capacidades deverão ser potencializadas para superar problemas e empecilhos que surgirão no desempenho do papel de pesquisadores qualitativos na sociedade atual? Por se tratar de profissionais da área da saúde, foi importante pensar como os elementos do processo de cuidar se fariam presentes e exigentes de reflexão em torno de estratégias no alcance de um cuidado ético e competente (LANDY et al., 2016). Consideramos, pois, a necessidade de formar pesquisadores e, ao mesmo tempo, estabelecer em sala de aula um espaço de construção coletiva.

Assim, traçar os objetivos das atividades pedagógicas dos encontros se tornou determinante do ato de elaborar e executar um plano, como espaço de criar as possibilidades para viver uma experiência docente na perspectiva de quem ensina e aprende enquanto ensina. As perguntas serviram como norteadoras do nosso autoconhecimento como pesquisadoras que optam pela abordagem qualitativa e foram facilitando a indicação e a seleção dos outros elementos que constituem o plano, como as estratégias de ensino, recursos e avaliação. $\mathrm{O}$ Quadro 1 apresenta a síntese do processo de planejamento:

\section{Quadro 1 - Planejamento realizado para os encontros entre docentes e discentes}

\begin{tabular}{|l|l|l|}
\hline Encontro & Objetivos da Atividade Pedagógica & Questões norteadoras \\
\hline $\mathbf{1}^{\mathbf{0}}$ Encontro & $\checkmark$ Propiciar reflexão teórico-prática sobre & O que você já sabe sobre \\
& $\begin{array}{l}\text { os princípios básicos regentes da pesquisa } \\
\text { qualitativa, evidenciando os aspectos } \\
\text { teórico-metodológicos; }\end{array}$ & $\begin{array}{l}\text { qualitativa? } \\
\text { O que você ainda quer saber } \\
\text { sobre métodos e técnicas em }\end{array}$ \\
\hline
\end{tabular}


Pessoa, Sousa e Machado / Experiência docente no ensino da disciplina de metodologia da pesquisa qualitativa na pós-graduação

\begin{tabular}{|c|c|c|}
\hline & $\begin{array}{l}\checkmark \text { Reforçar, nas discussões, aspectos } \\
\text { teórico-metodológicos; a construção } \\
\text { metodológica; o significado de métodos; } \\
\checkmark \text { Apresentar as múltiplas possibilidades } \\
\text { como caminhos já trilhados. }\end{array}$ & pesquisa qualitativa? \\
\hline $2^{\circ}$ Encontro & $\begin{array}{l}\checkmark \text { Estimular a leitura de textos que } \\
\text { apresentem proposta de pesquisa } \\
\text { quantitativo-qualitativa; } \\
\checkmark \text { Discorrer sobre estratégias de } \\
\text { investigação que contemplem análises } \\
\text { quantitativas e qualitativas de forma } \\
\text { complementar. }\end{array}$ & $\begin{array}{l}\text { Quais são as características dos } \\
\text { artigos que se utilizam de } \\
\text { elementos da abordagem } \\
\text { quantitativa e qualitativa? } \\
\text { Quais estratégias de } \\
\text { investigação são utilizadas de } \\
\text { modo complementar nas } \\
\text { pesquisas qualitativas e } \\
\text { quantitativas? }\end{array}$ \\
\hline $3^{\circ}$ Encontro & $\begin{array}{l}\checkmark \text { Apresentar os recursos metodológicos } \\
\text { desenvolvidos na abordagem qualitativa } \\
\text { aplicada ao campo de estudos de saúde; } \\
\checkmark \text { Refletir sobre as possibilidades de } \\
\text { desenvolvimento de projetos de pesquisa } \\
- \text { dissertações e teses - no campo de } \\
\text { estudos em saúde, que contemplem } \\
\text { objetos passíveis de análise qualitativa; } \\
\checkmark \text { Encaminhar o trabalho de campo - } \\
\text { trabalho de mapeamento das pesquisas } \\
\text { qualitativas - e teses do programa. }\end{array}$ & $\begin{array}{l}\text { Quais são as possíveis } \\
\text { aplicações da abordagem } \\
\text { qualitativa no campo de } \\
\text { estudos da saúde? } \\
\text { De que modo os objetos de } \\
\text { estudo no campo da saúde são } \\
\text { passíveis de análise por meio } \\
\text { de recursos qualitativos? }\end{array}$ \\
\hline $4^{\circ}$ Encontro & $\begin{array}{l}\checkmark \text { Apresentar os trabalhos em uma roda de } \\
\text { conversa; } \\
\checkmark \text { Estabelecer nexos entre problema } \\
\text { identificado, questão norteadora, } \\
\text { métodos e técnicas de coleta, e análise de } \\
\text { dados em uma pesquisa qualitativa. }\end{array}$ & $\begin{array}{lrr}\text { Qual é a percepção dos } & \text { dõ } \\
\text { discentes em relação aos } \\
\text { elementos } & \text { metodológicos } \\
\text { pertinentes } & \text { aos estudos } \\
\text { qualitativos? } & & \end{array}$ \\
\hline $5^{\circ}$ Encontro & $\begin{array}{l}\checkmark \text { Aplicar a técnica de grupo focal; } \\
\checkmark \text { Encaminhar o trabalho de campo } \\
\text { (entrevistas, transcrição e análise). }\end{array}$ & $\begin{array}{l}\text { Será a técnica de grupo focal } \\
\text { um recurso adequado na } \\
\text { obtenção de informações? }\end{array}$ \\
\hline $6^{\circ}$ Encontro & $\checkmark$ Apresentar trabalhos de campo. & $\begin{array}{lcr}\text { Quais são } & \text { as } & \text { críticas e } \\
\text { sugestões } & \text { aos } & \text { trabalhos } \\
\text { analisados? } & & \\
\end{array}$ \\
\hline $7^{\circ}$ Encontro & $\begin{array}{l}\checkmark \text { Apresentar trabalhos de campo; } \\
\checkmark \text { Avaliar a disciplina. }\end{array}$ & $\begin{array}{lcr}\text { Quais são } & \text { as } & \text { críticas e } \\
\text { sugestões } & \text { aos } & \text { trabalhos } \\
\text { analisados? } & & \\
\end{array}$ \\
\hline
\end{tabular}

Fonte: Elaborado pelas autoras.

Ainda que os objetivos no quadro sejam considerados ações a serem realizadas, podemos dizer que a partir deles tivemos a oportunidade de parar e refletir a respeito da experiência docente no sentido da paixão, da atenção, da escuta, da abertura, da disponibilidade, da sensibilidade e da exposição. Esta experiência nos deu o real como singular e ao mesmo tempo nos singularizou. Embora tenha enfrentado o mesmo acontecer educativo, cada uma viveu o desconhecido, inclusive de desenvolver a docência conjuntamente sem prever como 
Pessoa, Sousa e Machado / Experiência docente no ensino da disciplina de metodologia da pesquisa qualitativa na pós-graduação

atuaria, concomitantemente, em sala de aula. As perguntas nos fizeram admitir o não sabido, com o limite do que sabemos, e isto ficou evidente em vários momentos quando, em uma relação solidária, solicitávamos a vivência e sabedoria umas das outras. Para Domingo (2013), isto significa se abrir à possibilidade de experiência como relação respeitosa com as pessoas e seus processos de aprendizagem. Pensar sobre o que foi experimentado, necessita de um conhecimento pedagógico sempre em fluxo e em movimento, o que é exigência da profissão de professor.

Abordamos a seguir elementos para elaboração de estudos sobre tal perspectiva teórica, com a intenção de provocar a reflexão sobre as possibilidades e impossibilidades da ação docente em pós-graduação ao optar pelos caminhos da experiência como referência durante a disciplina de Métodos e Técnicas em Pesquisa Qualitativa em um programa de pós-graduação stricto sensu em Saúde Coletiva.

\section{O PROCESSO DOS ENCONTROS E A INOVAÇÃO PEDAGÓGICA}

Cada encontro foi desenvolvido a partir de um roteiro composto por: diálogo inicial integrador, seguido de memória do encontro anterior para, na sequência, serem lançadas as perguntas do dia e iniciadas as atividades pedagógicas. As perguntas formuladas implicavam o envolvimento dos participantes na tarefa comum, inclusive indicando a realização de pesquisa e possíveis leituras fora de sala.

As duas perguntas do primeiro encontro trouxeram como conteúdo para o diálogo o saber prévio do grupo sobre método e técnicas de pesquisa qualitativa e suas curiosidades relacionadas ao tema. Na perspectiva da aprendizagem, a capacidade dos seres humanos para aprender a partir da experiência depende dos esquemas significativos que se utilizam para interpretá-la e atribuir-lhe significado (ZABALA, 2002). A complexidade da aprendizagem exige uma intensa atividade intelectual do aluno inserido no conjunto de interações educativas ocorridas em sala de aula e mais significativamente nas que o aluno mantém com o professor. Este, com suas intervenções, contribui questionando os conhecimentos iniciais, desencadeando reflexões sobre o próprio processo de aprendizagem.

Esse momento foi importante para a ação docente, pois trouxe informações sobre o conhecimento, sobre o grupo, sobre os seus interesses, sobre as expectativas, logo colaborando com a clareza dos objetivos, dos caminhos e dos meios, para que todas as ações pedagógicas tivessem como foco o aluno e o conhecimento a ser adquirido. As indagações levantadas pelos alunos foram: Quais as contribuições da pesquisa qualitativa para as questões sociais mais amplas? Como o método qualitativo pode agregar, justificar e contribuir para o método quantitativo, de forma a trabalharem juntos? Como identificar a melhor técnica em pesquisa qualitativa para apreensão do fenômeno a ser investigado? Quais os métodos mais alinhados à avaliação qualitativa de serviço de saúde? Para iniciar o diálogo, indagamos o que era método. Assumimos método como caminho que se faz ao percorrer a feitura da pesquisa e acrescentamos os ensinamentos de Morin (2001), que defende método como uma atividade pensante do sujeito, e que para ser estabelecido necessita de estratégia, iniciativa, invenção e arte. 
Pessoa, Sousa e Machado / Experiência docente no ensino da disciplina de metodologia da pesquisa qualitativa na pós-graduação

Para responder às indagações, poderíamos organizar apresentações em PowerPoint ou optar por apresentações já organizadas e tentar respondê-las, assumindo uma postura distante da concepção construtivista do conhecimento. Para nós, a inovação viria do debate contínuo com os alunos e da crença de que ensinar não é transmitir conhecimento, mas sim criar possibilidades para a sua produção (FREIRE, 1996). Assim, era necessário oferecer subsídios antecipadamente, o que foi feito pela escolha de artigos publicados em periódicos, cujos métodos e técnicas utilizados pertenciam à vertente qualitativa e quantitativa. Eles foram encaminhados, previamente, por e-mail e colocados em discussão no segundo encontro. Contamos com as ideias de Magalhães, Agnol e Marck (2013); Brito-Silva et al. (2014); McCallum, Menezes e Reis (2016) e Sousa et al. (2015) para discussão e apresentação de investigações desenvolvidas, complementarmente, com análises quantitativas e qualitativas. Como qualquer prática pedagógica que respeite e valorize o saber do aluno, o resultado do exercício proposto dependeria, em muito, do discente. Era importante que os alunos se sentissem motivados em ler o material selecionado, e, ainda, criticar, sugerir ou associar o conteúdo ao seu objeto de estudo.

Nosso desejo era renovar o espaço da sala de aula e seus atores, na desconstrução da verticalização entre docente e discente, ou, ainda, na limitada reprodução de conteúdo em um monólogo interminável de recomendações, tornando como espaço de construção de conhecimento, os discentes e docentes, em uma totalidade dinâmica (SOUSA, 2013).

Foi pensada, assim, a possibilidade de convidar alunos egressos para apresentação de suas teses e de discussão relacionada aos métodos e técnicas qualitativas, utilizadas em pesquisas vinculadas ao programa em questão. $\mathrm{O}$ terceiro e quarto encontros foram destinados a receber os convidados escolhidos. O critério de elegibilidade foi o arcabouço teóricometodológico desenvolvido pelos autores e sua relação com a realidade da qual emergiram os objetos de estudo e a proposta criativa para apresentação dos resultados.

Uma das pesquisas apresentadas trouxe a cartografia que, embora relativamente nova no Brasil, possibilitou a construção de importantes trabalhos na área da enfermagem. Das pistas do método cartográfico, foi discutida a inseparabilidade entre conhecer e fazer, entre pesquisar e intervir (SILVA, 2012). Outra pesquisa, no seu caminho metodológico, inspirou-se na sociopoética que reconhece, por princípio, o corpo como fonte de saber e legitima saberes oriundos da vivência e das práticas, para investigar a coprodução da integralidade na atenção à saúde na tessitura do vínculo entre profissionais e usuários do SUS. Com o uso de dispositivos específicos, a sociopoética convida, reconhece e compromete os sujeitos da pesquisa como corresponsáveis pela produção do conhecimento promovendo um diálogo transdisciplinar pela fertilização mútua entre Arte e Ciência (BARBOSA, 2015).

Esses momentos, em sala de aula, foram de significativa aprendizagem para todos. Os relatos das experiências, a exposição dos obstáculos encontrados e o compartilhar de ações exitosas trouxeram a percepção de que fazer pesquisa envolve muito mais do que a mera aplicação de técnicas em torno de uma abordagem previamente selecionada. Produzir conhecimento, por meio do ato de pesquisar, é uma atitude humana, na qual inúmeros aspectos devem ser considerados, inclusive nossa falibilidade. Os relatos demostraram o quanto a pesquisa tocou cada um dos alunos, trazendo sentido ao seu papel de pesquisador ao utilizar da abordagem qualitativa. 
Pessoa, Sousa e Machado / Experiência docente no ensino da disciplina de metodologia da pesquisa qualitativa na pós-graduação

Outra estratégia utilizada incentivou os doutorandos a mapearem pesquisas qualitativas, tais como teses do programa. A aposta foi envolvê-los nas experiências de outros atores, acreditando que os nossos saberes resultam também do compartilhar experiências de outros e que a aprendizagem experiencial é um meio poderoso de elaboração e integração do saber-fazer e dos conhecimentos. Os alunos foram orientados para esta tarefa no terceiro encontro e apresentaram o resultado em uma roda de diálogo no quarto encontro, quando foram discutidos métodos como pesquisa-ação, etnografia, estudo de caso.

No quinto encontro, foi aplicada a técnica de grupo focal, tendo como participantes os discentes da disciplina. A atividade requereu planejamento prévio, com atenção a detalhes como: local, definição das questões para discussão e atribuição de funções para cada uma de nós, docentes, que estávamos invadidas por uma significativa motivação diante da possibilidade de melhorarmos nossa própria prática na utilização de técnica tão complexa e relevante na obtenção de informações no espaço dos estudos qualitativos.

A percepção de que somente a descrição teórica da técnica de grupo focal em sala de aula não seria suficiente para seu uso posterior em situações de pesquisa, orientou a busca de outra estratégia pedagógica. Assim, a inserção dos alunos, no papel de participantes de um estudo, ofereceu a oportunidade de experienciar algo único. A estruturação das etapas e distribuição de papéis entre docentes imprimiram um caráter realístico à atividade. $\mathrm{O}$ cuidado com minúcias (lanche, canetas coloridas, cartolinas, crachá de identificação e a reserva do espaço) demonstrou a seriedade e empenho da atividade.

A técnica de grupo focal se caracteriza por seu potencial exploratório da realidade, que abriga o objeto de estudo, permitindo a livre expressão de opiniões e obtenção de informações (GATTI, 2012). Esta técnica coaduna, portanto, com uma característica marcante das pesquisas qualitativas: a possibilidade de conhecer de modo mais amplo as vivências dos atores sociais que compartilham conosco, os pesquisadores, suas experiências de vida (TURATO, 2005).

São aspectos a serem considerados para efetividade dessa técnica: a postura do moderador em favorecer a participação de todos os integrantes; a observância de um ambiente agradável e sem ruídos externos; o conforto e a privacidade necessários ao compartilhamento de informações relevantes; além da formulação da questão norteadora para início da atividade.

No quinto encontro, os alunos foram recepcionados e acolhidos pelas professoras para a realização de um grupo focal. Todos se acomodaram em torno de uma mesa redonda, em cadeiras confortáveis, onde a visibilidade de cada um dos participantes se fazia possível. Providenciamos um lanche, que ficou disposto sobre a mesa e ao alcance de todos, não se fazendo necessário levantar para acessá-lo.

A docente titular da disciplina pactuou com os participantes algumas regras simples para a condução da prática, como: todos deveriam ficar à vontade para falar e compartilhar suas impressões e opiniões; o tempo seria controlado para que a atividade acontecesse no horário estabelecido; os diálogos seriam gravados (o grupo foi informado e anuiu); as docentes, que auxiliavam a prática, ficariam encarregadas de registrar pontos merecedores de esclarecimentos posteriores, assim como observariam a linguagem não verbal utilizada pelo grupo.

Para uma maior similitude com a prática real, os participantes foram convidados a assinar um Termo de Consentimento Livre e Esclarecido no qual se encontravam elementos necessários ao cumprimento dos aspectos éticos em pesquisas com seres humanos. Tal 
Pessoa, Sousa e Machado / Experiência docente no ensino da disciplina de metodologia da pesquisa qualitativa na pós-graduação

providência objetivou demonstrar a responsabilidade do pesquisador em manter o participante de estudos científicos informado em relação aos procedimentos de obtenção de dados, além dos riscos e benefícios inerentes.

Após as explicações, foi lançada ao grupo a questão norteadora: "Quais foram suas principais motivações na escolha da pós-graduação na área da Saúde Coletiva?" Estabeleceuse, então, uma estrutura dialógica excepcionalmente rica, com compartilhamento de expectativas individuais e coletivas em torno da formação do pesquisador no espaço da pósgraduação stricto sensu. O processo seletivo para o ingresso, o relacionamento com o orientador e a disposição das disciplinas na proposta curricular foram alguns dos tópicos verbalizados e colocados em discussão. Ressaltamos que as intervenções da mediadora aconteciam de modo pontual, quando se fazia necessário algum esclarecimento.

Como pactuado, mantivemos um registro continuado de elementos merecedores de atenção; não houve determinação prévia do que deveria ser observado por cada uma de nós, mas foi interessante a percepção singular e rica de significados resultantes de nossas experiências individuais.

Após os participantes expressarem que se sentiam contemplados em suas falas, a mediadora abriu espaço para nossas colocações. Nesse momento, oferecemos uma ressignificação do dito e do não dito. Encerramos a atividade fecundos e motivados: o desejo de construir uma pós-graduação forte e comprometida com a formação responsável era um apelo em comum, que exige a implicação de docentes e discentes. $\mathrm{O}$ envolvimento e a participação do grupo foram notórios, caracterizando a importância de tal tipo de experiências, pelo fato desta constituir um referencial que ajuda a avaliar uma situação, uma atividade, um acontecimento novo, com novos significados em nossas vidas (JOSSO, 2004). A autora defende que, se a aprendizagem experiencial é um meio poderoso de elaboração do saber-fazer e dos conhecimentos, o seu domínio pode se tornar um suporte eficaz de transformação. Josso (2004) lembra que uma experiência formadora é uma aprendizagem articulada, hierarquicamente, saber-fazer e conhecimento, funcionalidade e significação, técnicas e valores em um espaçotempo, que oferece a cada um a oportunidade de uma presença para si e para a situação, por meio da mobilização de uma pluralidade de registro.

Larrosa (2014) acrescenta que experiência é, em primeiro lugar, um encontro ou uma relação com algo que se experimenta, se prova. Foi nossa presença e disponibilidade para a situação que nos fizeram reconhecer esta experiência como formadora de pesquisador qualitativo, de docente, de ser humano, pois ela nos propulsionou aprender a ouvir, por excelência. Nesse sentido, Contreras e Lara (2010) defendem que experiência educacional não é um objeto do qual o pesquisador se distancia para conhecê-lo objetivamente.

Na sequência do programa, os sexto e sétimo encontros destinaram-se à apresentação dos resultados do trabalho de campo, constituindo em conteúdo precioso do diálogo para o desfecho da disciplina. Esta prática possibilitou aos alunos o desenvolvimento de um roteiro para realização de entrevistas não diretivas com oito egressos do Doutorado em Saúde Coletiva com a elaboração de uma rede interpretativa das motivações para ingresso no curso, dificuldades e potencialidades observadas, além de sugestões dadas para melhoria. O conteúdo do nosso diálogo também serviu para nos autoavaliarmos como envolvidas na formação dos egressos. 
Pessoa, Sousa e Machado / Experiência docente no ensino da disciplina de metodologia da pesquisa qualitativa na pós-graduação

O trabalho de campo se constitui numa etapa essencial da pesquisa qualitativa que, a rigor, não poderia ser pensada sem esta etapa (MINAYO, 2008). Pelos depoimentos dos alunos, houve um acerto pedagógico na realização desta tarefa, pela possibilidade da vivência em grupo e por colocá-los diante de situações novas. Nós, professoras, também fomos lançadas ao longo dos sete encontros, em situações inéditas, que exigiram produção de novas ideias em face ao que acontecia no processo grupal, fonte de ensino e aprendizagem permanentes.

$\mathrm{Na}$ avaliação da disciplina, tentamos abrir espaço em cada encontro para os alunos se colocarem, dessa forma, a avaliação formativa acontecia. Para efeito do conceito final, consideramos a participação, os trabalhos individuais e de grupos realizados e apresentados nos sete encontros. Para os alunos, tanto os encontros presenciais com as professoras quanto o trabalho de campo realizado pelo grupo foram experiências significativas de muita aprendizagem. As atividades propostas foram apontadas como fonte de aprendizagem em todas as distintas etapas, pois, além de entrevistarem, reuniram-se em grupo para organizar e analisar os resultados, elaborando um relatório único.

\section{OS SIGNIFICADOS DA AÇÃO DOCENTE}

A realização das ações se deu de forma orgânica, ou seja, integrada e como componente de um único organismo, com a participação das docentes e da professora supervisora, responsável pela disciplina, em todos os momentos. O processo de ensino se caracterizou pelo coletivo e, com uma visão complexa de aprendizagem, favoreceu o movimento de formar, aperfeiçoando-se. Nesta perspectiva, apontamos a seguir o que apreendemos de significados para a ação docente, acreditando nos ensinamentos de Freire (1996, p. 26) quando afirma: "ensinar inexiste sem aprender".

O conhecimento prévio do estudante, ao ser considerado, colabora no processo de formar, aperfeiçoando-se na docência. Instaura-se um movimento de reflexividade para o docente e para o discente, desencadeando, em ambos, o processo de estudo. As respostas para as perguntas realizadas no primeiro encontro foram analisadas em um movimento de pesquisaformação, fazendo da sala de aula um espaço dinâmico de troca de experiências e diálogo com a realidade na qual os objetos de estudo se manifestam.

A aproximação com relatos de experiências de pesquisa possibilita a reflexão teóricoprática de docentes e discentes. Com isso, ocorre o estímulo à análise crítica e à proposição de outros modos de pensar, novas soluções para antigos problemas.

O relato de experiências dos pesquisadores egressos aguçara o interesse dos estudantes. A apropriação da realidade intermediada pelo olhar do outro se mostrou como possibilidade pedagógica positiva para a consolidação de estratégias e o uso de técnicas no desenvolvimento de estudos.

O exercício prático de técnicas de pesquisa consolida o aprendizado, aproximando a teoria da prática. $\mathrm{O}$ envolvimento direto dos participantes na atividade de executar uma determinada técnica torna a experiência mais efetiva e concreta.

A vivência desta experiência por docentes em estágio pós-doutoral, ao compreender estágio como formação continuada, fez-se desafiadora mesmo para aqueles que já exercem o magistério. A dinâmica de formação contínua pressupõe um movimento dialético, de criação 
Pessoa, Sousa e Machado / Experiência docente no ensino da disciplina de metodologia da pesquisa qualitativa na pós-graduação

constante do conhecimento, do novo, a partir de superação (negação e incorporação) do já conhecido (PIMENTA, 1997; PIMENTA; LIMA, 2004). Foi possível inovar na docência por meio de uma atitude pedagógica investigativa, que envolve a reflexão e a intervenção, além de superar a dicotomia entre teoria e prática. $\mathrm{O}$ estágio pós-doutoral poderá representar espaço de excelência para pesquisa da prática docente, com a possibilidade de inserção em situações concretas de reflexão crítica, compreensão e problematização de situações que o estagiário observa.

\section{CONSIDERAÇÕES FINAIS}

Ao término da experiência relatada, foi possível constatar que, para nós, docentes em estágio pós-doutoral, a oportunidade de participar de uma experiência de ensino-aprendizagem na disciplina de Métodos e Técnicas em Pesquisa Qualitativa representou a abertura de horizontes e reavaliação de nossa própria prática docente e de nossa própria prática como pesquisadoras. Isto decorreu de um duplo desafio: ver a disciplina como espaço formativo e ensinar um conteúdo também deixado ainda à margem - a pesquisa qualitativa. A experiência não nos fez refletir somente sobre a formação docente, de uma forma geral, mas, especialmente, realçar a nossa disposição para a pesquisa. Indagações foram permanentes: como, quando e quem tem formado os pesquisadores que escolhem utilizar-se da abordagem qualitativa? Se esta formação tem acontecido normalmente na pós-graduação, que postura o professor tem adotado nessa experiência educativa? Que referencial norteia sua ação docente?

Essas questões, entre outras, apontam para o "inacabamento" da nossa formação docente, trazendo pistas para novas experiências. Nesse sentido, evidenciamos que, oriundas de instituições de ensino superior e distintas e com atuação em áreas do conhecimento diferentes, como Pedagogia e Enfermagem, nossa experiência prática convergiu de modo positivo para que o processo de planejamento, ensino e avaliação fossem etapas compartilhadas, com ensaios interdisciplinares. Além da consolidação de conhecimentos obtidos por meio do estágio pós-doutoral, o repensar de práticas pedagógicas e o reencontro com significados outros, mostrou-se como ganho positivo que, inquestionavelmente, consolidará a práxis docente das autoras. Inclusive o processo vivido na sistematização deste texto.

Outro aspecto determinante foi o reconhecimento, da professora supervisora, de nossas possibilidades, concepções e juízos prévios nas etapas de composição da disciplina, que consideraram a criatividade e inventividade de cada uma de nós. Embora com funções distintas e de responsabilidades particulares, o diálogo foi circular, sem arrogância intelectual, favorecendo que cada uma se expusesse como sujeitos da experiência buscando saber mais em comunhão.

A ampliação do espaço em sala de aula para além dos limites de estratégias formatadas como válidas, nos fez descobrir outras possibilidades, inclusive reconhecer que as rodas de diálogo podem ser adequadas dentro de uma compreensão de educação como experiência, pois as salas de pós-graduação representaram uma boa ambiência de encontro, confronto de saberes, fortalecimento das ideias, e construção em cooperação com o outro. Também podemos evidenciar como significativa a participação de outros atores sociais narrando a suas experiências e a proposta crítica e reflexiva predominante ao olharmos a realidade. Esses foram 
Pessoa, Sousa e Machado / Experiência docente no ensino da disciplina de metodologia da pesquisa qualitativa na pós-graduação

elementos agregadores à experiência.

Conhecer, dialogar e refletir sobre novos significados, construir novos sentidos, são ferramentas importantes para aqueles que ousam ser confrontados com as mudanças advindas de um período sabático de estágio pós-doutoral. Mudanças que possibilitam reconhecer nosso "inacabamento" e, para além-experiência, vislumbram olhares diferentes se entrelaçando, além de mãos em comunhão em um movimento circular em favor da construção de novas práticas docentes no ensino de pesquisa qualitativas em todos os graus de ensino.

\section{Referências}

ANASTASIOU, L. G. C.; ALVES, L. P. (Org.). Processos de ensinagem na universidade: pressupostos para as estratégias de trabalho em aula. 6. ed. Joinville: Univille, 2010.

BARATA, R. B.; SANTOS, R. V. Ensino de pós-graduação em Saúde Coletiva: situação atual e desafios para o futuro. RBPG, Brasília, DF, v. 10, n. 19, p. 159-183, 2013.

BARBOSA, M. I. S. O vínculo na atenção primária do Sistema Único de Saúde do Brasil. 2015. 413 f. Tese (Doutorado em Saúde Coletiva) - Centro de Ciências da Saúde, Universidade Federal do Ceará, Fortaleza, 2015.

BASSORA, J. B.; CAMPOS, C. J. G. Metodologia clínico-qualitativa na produção científica no campo da saúde e ciências humanas: uma revisão integrativa. Revista Eletrônica de Enfermagem, Goiânia, v. 12, n. 4, p. 753-760, 2010. Disponível em: 〈https://goo.gl/mdeP3u>. Acesso em: 23 jan. 2017.

BATISTA, N. A.; SILVA, S. H. S. O professor de Medicina. 2. ed. São Paulo: Loyola, 2001.

BATISTA, N. A. et al. A abordagem qualitativa na pesquisa em educação médica: investigação qualitativa em saúde. In: CONGRESSO IBERO-AMERICANO EM INVESTIGAÇÃO QUALITATIVA, 2016, Barcelona. Anais... Barcelona, 2016. v. 2, p. 912-920.

BENJUMEA, C. C. The quality of qualitative research: from evaluation to attainment. Texto \& Contexto - Enfermagem, Florianópolis, v. 24, n. 3, p. 883-890, 2015.

BONDÍA, J. L. Notas sobre a experiência e o saber de experiência. Revista Brasileira de Educação, Rio de Janeiro, n. 19, p. 20-28, 2002.

BOSI, M. L. M. Pesquisa qualitativa em saúde coletiva: panorama e desafios. Ciência \& Saúde Coletiva, Rio de Janeiro, v. 17, n. 3, p. 575-586, 2012.

Formar pesquisadores qualitativos em saúde sob o regime produtivista: compartilhando inquietações. Revista Facultad Nacional de Salud Pública, Medellin, v. 33, p. S30-37, 2015. Suplemento. 
Pessoa, Sousa e Machado / Experiência docente no ensino da disciplina de metodologia da pesquisa qualitativa na pós-graduação

BOSI, M. L. M.; MACEDO, M. A. Anotações sobre a análise crítica de discurso em pesquisas qualitativas no campo da saúde. Revista Brasileira de Saúde Materno Infantil, Recife, v. 14, n. 4, p. 423-432, 2014.

BRASIL. Ministério da Educação. Lei n ${ }^{\circ}$ 9.394, de 20 de dezembro de 1996. Estabelece as diretrizes e bases da educação nacional. Diário Oficial da União, Brasília, DF, 23 dez. 1996. Disponível em: <https://goo.gl/oXee3>. Acesso em: 23 jan. 2017.

BRITO-SILVA, K. et al. Integralidade no cuidado ao câncer do colo do útero: avaliação do acesso. Revista de Saúde Pública, São Paulo, v. 48, n. 2, p. 240-248, 2014.

CARVALHO, J. S. F. A crise na educação como crise da modernidade. In: AQUINO, J. G.; REGO, T. C. (Org.). Hannah Arendt pensa a educação: a educação em tempos sombrios. São Paulo: Segmento, 2014, Edição Kindle. posição 280-534.

CONTRERAS, J.; LARA, N. P. Investigar la experiencia educativa. Madrid: Morata, 2010.

CORREIA, A. O pensamento pode evitar o mal? In: AQUINO, J. G.; REGO, T. C. (Org.). Hannah Arendt pensa a educação: a educação em tempos sombrios. São Paulo: Segmento, 2014, Edição Kindle. posição 947-1163.

DOMINGO, J. C. El saber de la experiencia en la formación inicial del profesorado. Revista Interuniversitaria de Formación del Profesorado, Barcelona, v. 78, n. 27, p. 125-136, 2013.

FREIRE, P. Pedagogia do oprimido. Rio de Janeiro: Paz e Terra, 1987.

Pedagogia da autonomia. São Paulo: Cortez, 1996.

GANDIN, D. Planejamento como prática educativa. São Paulo: Loyola, 2005.

GATTI, B. A. Grupo focal na pesquisa em ciências sociais e humanas. Brasília, DF: Liber Livro, 2012.

HERNÁNDEZ, F. Cultura visual, mudança educativa e projeto de trabalho. Porto Alegre: Artmed, 2000.

JOSSO, M. C. Experiências de vida e formação. São Paulo: Cortez, 2004.

LANDY, R. et al. Educational strategies to enhance reflexivity among clinicians and health professional students: a scoping study. Forum: Qualitative Social Research Sozialforschung, Berlin, v. 17, n. 3, sept. 2016.

LARROSA, J. Tremores: escritos sobre experiência. Belo Horizonte: Autêntica, 2014.

MAGALHÃES, A. M. M.; DALL'AGNOL, C. M.; MARCK, P. B. Carga de trabalho da equipe de enfermagem e segurança do paciente-estudo com método misto na abordagem ecológica restaurativa. Revista Latino-Americana de Enfermagem, Ribeirão Preto, v. 21, p. 1-9, jan./fev. 2013. Número especial. 
Pessoa, Sousa e Machado / Experiência docente no ensino da disciplina de metodologia da pesquisa qualitativa na pós-graduação

MAGALHÃES, R. C. B. et al. Formação docente na pós-graduação stricto sensu: experiências na Universidade Federal do Rio Grande do Norte. Revista Brasileira de Pós-Graduação, Brasília, DF, v. 13, n. 31, p. 559-582, 2016.

MASETTO, M. Inovação no ensino superior. São Paulo: Loyola, 2012.

MC-CALLUM, C.; MENEZES, G.; REIS, A. P. O dilema de uma prática: experiência de aborto em uma maternidade pública de Salvador, Bahia. História, Ciências, Saúde-Manguinhos, Rio de Janeiro, v. 23, n. 1, p. 37-56, 2016.

MINAYO, M. C. S. O desafio do conhecimento: pesquisa qualitativa em saúde. 11. ed. São Paulo: Hucitec, 2008.

MORIN, E. Os sete saberes necessários à educação do futuro. São Paulo: Cortez, 2000.

Ciência com consciência. Rio de Janeiro: Bertrand Brasil, 2001.

PIMENTA, S. G. O estágio na formação de professores: unidade teoria e prática? São Paulo: Cortez, 1997.

PIMENTA, S. G.; ANASTASIOU, L. G. C. Docência no ensino superior. São Paulo: Cortez, 2002.

PIMENTA, S. G.; LIMA, S. L. Estágio e docência. São Paulo: Cortez, 2004.

SILVA, M. R. F. Linhas de cristalização e de fuga nas trilhas da Estratégia Saúde da Família: uma cartografia da micropolítica. 2012. 200 f. Tese (Doutorado em Saúde Coletiva) - Centro de Ciências da Saúde, Universidade Federal do Ceará, Fortaleza, 2012.

SOUSA, M. H. et al. Preenchimento da notificação compulsória em serviço de saúde que atendem mulheres que sofrem violência sexual. Revista Brasileira de Epidemiologia, São Paulo, v. 18, n. 1, p. 94-107, 2015.

SOUSA, M. S. Professor: a subjetividade do ser, do ensinar e do aprender. São Paulo: Livraria da Física, 2013.

SOUZA, C. T. V.; HORA, D. L. Produção de conhecimento em saúde na pesquisa clínica: contribuições teórico-práticas para a formação do docente. Revista Brasileira de PósGraduação, Brasília, DF, v. 11, n. 26, p. 1121-1135, 2014.

TAQUETTE, S. R.; MINAYO, M. C. S. Ensino-aprendizagem da metodologia de pesquisa qualitativa em medicina. Revista Brasileira de Educação Médica, Rio de Janeiro, v. 39, n. 1, p. 60-67, 2015.

TURATO, E. R. Métodos quantitativos e qualitativos na área da saúde: definições, diferenças e seus objetos de pesquisa. Revista de Saúde Pública, São Paulo, v. 39, n. 3, p. 507-514, 2005.

ZABALA, A. A prática educativa: como ensinar. Porto Alegre: Artmed, 1998. 
Pessoa, Sousa e Machado / Experiência docente no ensino da disciplina de metodologia da pesquisa qualitativa na pós-graduação

Enfoque globalizador e pensamento complexo: uma proposta para o currículo escolar. Porto Alegre: Artmed, 2002.

Recebido em 22/11/2016

Aprovado em 31/08/2017 